\title{
Profile of paediatric patients with pulmonary hypertension judged by responsiveness to vasodilators
}

\author{
Christine Houde, Desmond J Bohn, Robert M Freedom, Marlene Rabinovitch
}

\begin{abstract}
Objective-To describe the demographic and haemodynamic variables of children presenting with primary pulmonary hypertension or pulmonary hypertension appearing or persisting after surgical correction of congenital heart defects and to assess the acute effect of vasodilator drugs on their pulmonary vascular bed.

Design-Retrospective review.

Setting-Paediatric cardiology department and intensive care unit of a large tertiary centre.
\end{abstract}

Patients-Fourteen consecutive patients presenting with primary pulmonary hypertension (group 1) or pulmonary hypertension persisting or appearing late after complete surgical repair (group 2).

Intervention-Baseline haemodynamic measurements were taken in room air at rest and repeated in $100 \%$ oxygen. With constant monitoring of heart rate and pulmonary and systemic arterial pressures, patients were given serial intravenous, sublingual, or oral incremental doses of vasodilators (mean $4 \cdot 1$ trials per patient). The maximum effect of the drug was charted.

Main outcome measures-A positive response to acute vasodilator tests was defined as a decrease in mean pulmonary or mean systemic arterial pressure $>15 \%$ with the mean pulmonary artery pressure not reaching the systemic level and either no change or an increase in mean systemic arterial pressure. Haemodynamic variables between groups ( $1 v 2$, responders $v$ non-responders, patients experiencing or not experiencing adverse effects to vasodilators) were compared by a two tailed unpaired Student's $t$ test, and their survival curves were compared by the log rank statistic.

Results-Groups are small and definitive conclusions are difficult to draw, but the baseline haemodynamic assessments were not significantly different between group 1 and 2 or between responders and non-responders to vasodilators. Patients experiencing adverse effects had a higher pulmonary vascular resistance $(p=0.04)$ and wedge pressure $(p=0.02)$ than those without adverse effects. Of the vasodilators used, tolazoline, hydralazine, salbutamol, phentolamine, and phenoxybenzamine were ineffective. A positive response was seen in five of 13 patients given oxygen, in one of eight given prostacyclin, four of 12 given nifedipine, four of eight given diltiazem, one of six given captopril, and two of seven given glyceryl trinitrate. Estimates of survival of the population with primary pulmonary hypertension were $37 \%$ at one year and $12 \%$ at 2.5 years. Survival was significantly shorter in the non-responders than in the responders $(p=0.005)$. Conclusion-Children with primary pulmonary hypertension present to the cardiologist at a young age (five of eight were younger than 7 years) but with advanced pulmonary vascular disease and have a poor prognosis. $64 \%$ of group 1 and group 2 patients had a positive response to acute treatment with at least one vasodilator. Calcium channel blockers were the most effective agents. There was a positive response to drugs despite a negative response to acute treatment with oxygen. The survival of nonresponders was shorter than that of the responders.

(Br Heart f 1993;70:461-468)

Primary or unexplained pulmonary hypertension is still a puzzling disease in which there is likely to be more than one aetiology and pathophysiological mechanism. Since the first report published in 1976 describing the use of an isoproterenol infusion in treating primary pulmonary hypertension, ${ }^{1}$ numerous vasodilators have been tried. Unfortunately, with each vasodilator tried, there was considerable controversy over short and long-term efficacy and toxic side effects. ${ }^{2-5}$ Because primary pulmonary hypertension is rare in children, natural history studies are few as are long-term results of treatment with vasodilators. A correlation between structure and function in experimental animals suggests that a vasoconstrictive component of pulmonary hypertension may be superimposed upon a fixed component. This results initially from increased muscularity and later, intimal fibrosis and plexiform lesions. Moreover, it has been suggested that the vasoconstrictive component contributes to the progression of the structural abnormalities. ${ }^{6}$ It is appealing to suggest that vasodilator treatment in paediatric patients with primary pulmonary hypertension might prevent permanent lesions but this has never been proved. Equally uncertain is the efficacy of vasodilator treatments in 
Table 1 Clinical characteristics

\begin{tabular}{|c|c|c|c|c|c|c|c|}
\hline $\begin{array}{l}\text { Patient } \\
\text { No }\end{array}$ & $\begin{array}{l}\text { Age at } \\
\text { diagnosis }\end{array}$ & $\operatorname{Sex}$ & $\begin{array}{l}\text { Associated } \\
\text { conditions }\end{array}$ & Symptoms & $\begin{array}{l}\text { Heart } \\
\text { failure }\end{array}$ & $\begin{array}{l}\text { Congenital } \\
\text { heart disease }\end{array}$ & Surgery \\
\hline \multicolumn{8}{|c|}{ Group 1: primary pulmonary hypertension } \\
\hline 1 & $4 \cdot 1$ & $\mathbf{M}$ & \multirow{8}{*}{$\begin{array}{l}\text { Liver } \\
\text { Deafness }\end{array}$} & f, D, S & No & & \\
\hline 2 & $4 \cdot 4$ & $\mathbf{F}$ & & $\mathrm{D}, \mathrm{S}$ & Yes & & \\
\hline 3 & 4.9 & $\mathbf{F}$ & & & No & & \\
\hline 4 & $5 \cdot 8$ & $\mathbf{F}$ & & f, D & No & & \\
\hline 5 & $6 \cdot 7$ & $\mathbf{F}$ & & f, D & Yes & & \\
\hline 6 & 11.9 & $\mathbf{F}$ & & $\mathrm{f}, \mathrm{D}, \mathrm{S}, \mathrm{C}, \mathrm{H}$ & Yes (treated) & & \\
\hline 7 & 15 & $\mathbf{M}$ & & $\mathrm{D}, \mathrm{S}, \mathrm{C}$ & No & & \\
\hline 8 & $16 \cdot 1$ & $\mathbf{F}$ & & f,D & Yes & & \\
\hline \multicolumn{8}{|c|}{ Group 2: secondary pulmonary hypertension } \\
\hline 1 & $2 \cdot 1$ & $\mathbf{F}$ & \multirow{7}{*}{$\begin{array}{l}\text { Left hemiface } \\
\text { hypoplasia } \\
\text { mental delay } \\
\text { Twin birth } \\
36 \text { week gestation } \\
\text { Cerebral } \\
\text { teratoma } \\
\text { Velo-occulo } \\
\text { facial syndrome }\end{array}$} & & Yes & ToF & \multirow{2}{*}{$\begin{array}{l}\text { 10m: R BT 2yr: repair } \\
\text { 2yr: VSD closure, division } \\
\text { ligamentum arteriosum }\end{array}$} \\
\hline 2 & $2 \cdot 8$ & $\mathbf{M}$ & & & No & Vascular ring, VSD & \\
\hline 3 & $4 \cdot 7$ & $\mathbf{F}$ & & & No & Transient myocar- & 4yr: 3m PDA ligation \\
\hline J & & & & & & dial ischaemia, PDA & 4yr. JM TDA IIgaduOn \\
\hline 4 & $5 \cdot 7$ & $\mathbf{F}$ & & f, D & No & ToF & 17m: R BT 4yr: repair \\
\hline 5 & $5 \cdot 9$ & $\mathbf{M}$ & & $f, D, S, C$ & No & VSD,COA & \multirow{2}{*}{$\begin{array}{l}\text { 14d: COA repair } 2 \mathrm{~m}: \text { PA band } \\
\text { 2yr: PA plasty, VSD closure } \\
\text { 9m: Repair }\end{array}$} \\
\hline 6 & $11 \cdot 1$ & $\mathbf{F}$ & & f & No & $\begin{array}{l}\text { AP window, inter- } \\
\text { rupted aortic arch }\end{array}$ & \\
\hline
\end{tabular}

«Necropsy showed periportal vein thrombosis. AP, aortopulmonary; $C$, chest pain; COA, coarctation of the aorta; $D$, dyspnoea; $d$, days; $f$, fatigue; $F$, female; $H$, haemoptysis; $M$, male; m, months; PA, pulmonary artery; PDA, patent ductus arteriosus; $R$ BT, right Blalock-Taussig shunt; $R V$, right ventricle; S, syncope; ToF, tetralogy of Fallot; VSD, ventricular septal defect.

patients with secondary pulmonary hypertension, which is a complication of congenital heart defects and chronic lung disease.

In 1983 we began to assess the acute response to vasodilators in all consecutive patients with either primary or secondary pulmonary hypertension. We examined whether responders to oxygen or vasodilator drugs differed from non-responders in their mode of presentation, severity of haemodynamic abnormalities, and long term outcome. Furthermore as lung transplantation might be a therapeutic option for some patients with this disease, ${ }^{7-9}$ we examined whether lack of response or adverse effects to treatment could serve as predictors of the patients with a poorer prognosis.

\section{Patients and methods PATIENTS}

We report the results from 14 patients with pulmonary hypertension (mean pulmonary artery pressure at rest $>25 \mathrm{~mm} \mathrm{Hg}$ ) who underwent a trial of acute vasodilator tests between March 1983 and June 1991. Patients were classified as group 1, primary or unexplained pulmonary hypertension, if no other causes of pulmonary hypertension could be found. ${ }^{10}$ Group 2 consisted of six patients older than one year in whom high pulmonary pressure persisted or recurred after complete surgical repair of a congenital heart defect. Table 1 gives clinical details. Table 2 shows preoperative haemodynamic assessment in group 2 patients. We excluded from our analysis more than 90 patients who over this time received vasodilator treatment for transient postoperative pulmonary hypertension or in whom pulmonary hypertension was associated with unoperated congenital heart defects, residual cardiac lesions, trisomy 21, metabolic diseases, or pulmonary disease.

\section{METHODS}

Informed parental and, when applicable, patient consent was obtained with a protocol approved by the Human Subjects Review Committee of the Hospital for Sick Children, Toronto, Canada. No patients were receiving vasodilator, antiplatelet, or anticoagulant medication before the study. The two patients given drugs to prevent heart failure had their medications withheld the morning of the catheterisation study. After a fasting period of eight hours, intramuscular premedication (meperidine and promethazine or morphine) was given and right heart catheterisation was carried out under local anaesthesia with the patient supine at rest in room air,

Table 2 Preoperative haemodynamic values for group 2

\begin{tabular}{|c|c|c|c|c|c|c|c|}
\hline $\begin{array}{l}\text { Patient } \\
\text { No }\end{array}$ & $\begin{array}{l}\text { Age at } \\
\text { catheter } \\
\text { study }\end{array}$ & $\begin{array}{l}P A P \\
(m m \mathrm{Hg})\end{array}$ & $\begin{array}{l}S A P \\
(m m H g)\end{array}$ & $R_{\text {flood units } m^{2} \text { ) }}$ & $Q_{p} / Q_{s}$ & $\begin{array}{l}\text { Time between } \\
\text { final surgery and } \\
\text { diagnosis of } P H\end{array}$ & $\begin{array}{l}\text { Lung biopsy* } \\
\text { at initial surgery }\end{array}$ \\
\hline 1 & $2 \mathrm{yr}$ & $\begin{array}{l}65 / 35 \\
45\end{array}$ & $\begin{array}{l}85 / 55 \\
60\end{array}$ & $5 \cdot 1$ & $2 \cdot 3 / 1$ & 11 days & \multirow{4}{*}{$\begin{array}{l}\text { H-E grade 0/ } \\
\text { morphometric 0 } \\
\text { H-E grade IV/ } \\
\text { morphometric C severe } \\
\text { H-E grade I-II/ } \\
\text { morphometric B severe } \\
\text { NA }\end{array}$} \\
\hline 2 & $2 \mathrm{yr}$ & $\begin{array}{l}78 / 32 \\
52\end{array}$ & $\begin{array}{l}87 / 50 \\
62\end{array}$ & $8 \cdot 1$ & $1 \cdot 8 / 1$ & $7 \mathrm{~m}$ & \\
\hline 3 & $4 \mathrm{yr} 3 \mathrm{~m}$ & $\begin{array}{l}100 / 56 \\
72\end{array}$ & $\begin{array}{l}100 / 50 \\
70\end{array}$ & 10 & & $3 \mathrm{~m}$ & \\
\hline 4 & $4 \mathrm{yr}$ & NA & $\begin{array}{c}100 / 65 \\
82\end{array}$ & NA & NA & 1 y $6 \mathrm{~m}$ & \\
\hline 5 & $2 \mathrm{yr}$ & $\begin{array}{l}40 / 15 \\
25\end{array}$ & $\begin{array}{l}100 / 70 \\
80\end{array}$ & NA & $0.9 / 1$ & 3 y $9 \mathrm{~m}$ & \multirow{2}{*}{$\begin{array}{l}\text { H-E grade } 1 \\
\text { morphometric B severe } \\
\text { NA }\end{array}$} \\
\hline 6 & $8 \mathrm{~m}$ & $\begin{array}{l}94 / 55 \\
66\end{array}$ & $\begin{array}{l}96 / 60 \\
78\end{array}$ & $8 \cdot 7$ & $2 \cdot 3 / 1$ & 10 y $3 \mathrm{~m}$ & \\
\hline
\end{tabular}

*For details of biopsy see Heath and Edwards ${ }^{11}$ and Rabinovitch et al. ${ }^{12}+$ Dye curve, injecting in the aorta, sampled in the main pulmery pulmonary artery showed left to right shunt. No rght to pressure; PH, pulmonary hypertension; $Q_{0} Q_{j}$; pulmonary to systemic flow ratio; $R_{p}$, pulmonary vascular resistance index; $S A P$, pressure; PH, pulmonary
systemic artery pressure. 
Table 3 Baseline haemodynamic values

\begin{tabular}{|c|c|c|c|c|c|c|c|c|c|}
\hline $\begin{array}{l}\text { Patient } \\
\text { No }\end{array}$ & $\begin{array}{l}m R A P \\
(m m H g)\end{array}$ & $\begin{array}{l}m P A P \\
(m m H g)\end{array}$ & $\begin{array}{l}C I \\
\left(1 / \min m^{2}\right)\end{array}$ & $\begin{array}{l}\text { PVRI } \\
\text { (blood units } m^{2} \text { ) }\end{array}$ & $\begin{array}{l}\text { SVRI } \\
\text { (blood units } m^{2} \text { ) }\end{array}$ & $\begin{array}{l}M V \\
(\text { sat\%) }\end{array}$ & $\begin{array}{l}\mathrm{Ao} \mathrm{Po} \\
(\mathrm{mm} \mathrm{Hg})\end{array}$ & $\begin{array}{l}m P A \\
\text { wedge } P \\
(m m \mathrm{Hg})\end{array}$ & Outcome \\
\hline \multicolumn{10}{|c|}{ Group 1} \\
\hline $1^{\star}$ & 11 & 63 & $3 \cdot 8$ & $13 \cdot 3$ & $12 \cdot 2$ & - & $83^{*}$ & - & \multirow{9}{*}{$\begin{array}{l}\text { \In intensive care unit } \\
\$ 2.6 \mathrm{yr} \text { after trial } \\
\text { Alive } 5 \text { yr, NYHA class } 3 \\
\text { \$0.6 yr after trial } \\
\text { \$1 week after trial } \\
\$ 0.6 \mathrm{yr} \text { after trial } \\
\text { \$Transplantation } \\
\text { \$0.7 yr after trial }\end{array}$} \\
\hline $2 \ddagger$ & 9 & 50 & $3 \cdot 3$ & $13 \cdot 0$ & $19 \cdot 0$ & 51 & 53 & 7 & \\
\hline 3 & 3 & 55 & $3 \cdot 1$ & 16.5 & $19 \cdot 7$ & 67 & 77 & 2 & \\
\hline 4 & 6 & 100 & 2.9 & $40 \cdot 6$ & 28 & 48 & 85 & 5 & \\
\hline 5 & 7 & 80 & 2.5 & 26.5 & $24 \cdot 0$ & 45 & 66 & 14 & \\
\hline 6 & 8 & 90 & - & - & - & 58 & 73 & 12 & \\
\hline 7 & 7 & 100 & $1 \cdot 4$ & 61.9 & 61.9 & 60 & 106 & 12 & \\
\hline & 5 & 48 & - & - & - & & & & \\
\hline Mean (SD) $\dagger$ & $6(2)$ & $75(24)$ & $2 \cdot 6(0 \cdot 7)$ & $31 \cdot 7(20)$ & $\begin{array}{c}30.5(18) \\
\text { Group } 2\end{array}$ & $54(8)$ & $77(18)$ & $8(4)$ & \\
\hline 1 & 7 & 37 & 1.9 & $16 \cdot 8$ & $27 \cdot 8$ & 50 & 99 & 5 & \multirow{7}{*}{$\begin{array}{l}\text { Alive } 3.8 \text { yr NYHA class } 1 \\
\text { Alive } 8.5 \text { yr NYHA class } 3 \\
\$ 1 \cdot 1 \text { yr after trial } \\
\$ 0.4 \text { yr after trial } \\
\$ 2 \text { yr after trial } \\
\text { \& Reoperation }\end{array}$} \\
\hline 2 & 4 & 48 & $3 \cdot 7$ & 11.7 & 16.9 & 71 & 86 & 5 & \\
\hline 3 & 10 & 85 & $2 \cdot 7$ & $24 \cdot 8$ & $28 \cdot 0$ & 57 & 71 & 18 & \\
\hline 4 & 7 & 45 & 1.9 & $18 \cdot 3$ & $31 \cdot 4$ & 50 & 75 & 10 & \\
\hline 5 & & & & $41 \cdot 0$ & 34.0 & & & 10 & \\
\hline & 5 & 60 & $3 \cdot 3$ & $18 \cdot 2$ & $24 \cdot 4$ & 71 & 98 & & \\
\hline Mean (SD) & $7(2)$ & $59(20)$ & $2.5(0.8)$ & $21 \cdot 8(10)$ & $27(6)$ & $59(10)$ & 79 (16) & $7 \cdot 5(6)$ & \\
\hline
\end{tabular}

${ }^{\star}$ Because of critical condition patient was ventilated with $100 \% \mathrm{O}_{2}$ at time of study. †Mean (2SD) excluding patient 1 . $¥ \mathrm{PFO}$. $\$ \mathrm{DDead}$. AoPo $\mathrm{O}_{2}$ arterial partial pressure in oxygen; $\mathrm{CI}$, cardiac index; $m$ RAP, mean right atrial pressure; mPAP, mean pulmonary arterial pressure; $m$ PA wedge $\mathrm{p}$, mean pulmonary artery wedge pressure; MV, mixed venous; PVRI, pulmonary vascular resistance index; SVRI, systemic vascular resistance index; NYHA, New York Heart Association; w, week.

except for one patient who was intubated and ventilated with $100 \%$ oxygen because of his critical condition. Swan-Ganz catheters were inserted percutaneously through the femoral vein and manipulated into the pulmonary artery under fluoroscopic guidance and pressure monitoring. A temporary femoral arterial line was inserted in all but two patients in whom systemic blood pressure was measured by cuff. Heart rate and vascular pressures were monitored continuously. Mean right atrial, pulmonary arterial, pulmonary wedge, and systemic arterial pressures were obtained by electronic integration of the pressure signals with the midaxillary line as the reference. Arterial blood gases and mixed venous saturations were obtained. In no case was carbon dioxide raised and contributing to increased pulmonary artery pressure. Cardiac output was measured by the oxymetric principle of Fick with measured oxygen consumption or by an indicator dilution method and values were indexed according to the body surface area. Pulmonary and systemic vascular resistance indices were calculated with the standard formula. ${ }^{13}$ Table 3 shows details of the baseline haemodynamic assessment in each individual patient. Group 2 patients with a surgically corrected congenital heart defect had appropriate angiograms to rule out any residual defect. After a baseline haemodynamic assessment, patients were given $100 \%$ oxygen by mask for 10 minutes and all the measurements were repeated.

\section{Drug protocol}

Pulmonary arterial catheters were secured in place, femoral arterial lines removed, and all patients were transferred to the intensive care unit for the second part of the protocol. A small heparin filled radial artery cannula was inserted and heart rate, systolic, diastolic, mean pulmonary, and systemic arterial pressures were recorded continuously. Despite less sedation, baseline pulmonary and systemic vascular pressure and resistance values were similar to those in the catheter laboratory. After stabilisation, incremental doses of different drugs were given (table 4 ) to a maximal dose or until side effects occurred. The maximal dose given was documented by continuous pressure recording and was based on achieving no further reduction of the pulmonary to systemic artery pressure ratio if this had been documented at a lower dose or upon the appearance of adverse symptoms, such as a decrease in mean systemic arterial pressure by $>30 \%$ or an increase in heart rate

Table 4 Vasodilators used

\begin{tabular}{|c|c|c|c|c|c|}
\hline Medication & Route & $\begin{array}{l}\text { No of } \\
\text { trials }\end{array}$ & $\begin{array}{l}\text { Minimum } \\
\text { dose }\end{array}$ & $\begin{array}{l}\text { Maximum } \\
\text { dose }\end{array}$ & $\begin{array}{l}\text { Average } \\
\text { dose }\end{array}$ \\
\hline $\begin{array}{l}\text { Prostacyclin } \\
\text { Nifedipine } \\
\text { Nifedipine } \\
\text { Diltiazem }^{*} \\
\text { Diltiazem }^{\dagger} \\
\text { Tolazoline } \\
\text { Hydralazine } \\
\text { Salbutamol } \\
\text { Captopril } \\
\text { Glycyryl trinitrate } \\
\text { Phentolamine } \\
\text { Phenoxybenzamine } \\
\text { Amrinone }\end{array}$ & $\begin{array}{l}\text { IV } \\
\text { IV } \\
\text { SL } \\
\text { IV } \\
\text { O } \\
\text { IVs } \\
\text { IV } \\
\text { IV } \\
\text { O } \\
\text { IV } \\
\text { IV } \\
\text { IV } \\
\text { IV }\end{array}$ & $\begin{array}{l}8 \\
1 \\
12 \\
3 \\
6 \\
2 \\
6 \\
5 \\
6 \\
7 \\
2 \\
1 \\
1\end{array}$ & $\begin{array}{l}12 \mathrm{ng} / \mathrm{kg} / \mathrm{min} \\
0.2 \mathrm{mg} / \mathrm{kg} \\
7.5 \mu \mathrm{g} / \mathrm{kg} / \mathrm{min} \\
1 \mathrm{mg} / \mathrm{kg} \\
0.1 \mathrm{mg} / \mathrm{kg} \\
1 \mu \mathrm{g} / \mathrm{kg} / \mathrm{min} \\
0.23 \mathrm{mg} / \mathrm{kg} \\
1 \mu \mathrm{g} / \mathrm{kg} / \mathrm{min} \\
81 \mu \mathrm{g} / \mathrm{kg} / \mathrm{min} \\
-\end{array}$ & $\begin{array}{c}40 \mathrm{ng} / \mathrm{kg} / \mathrm{min} \\
1.3 \mathrm{mg} / \mathrm{kg} \\
30 \mu \mathrm{g} / \mathrm{kg} / \mathrm{min} \\
6 \mathrm{mg} / \mathrm{kg} \\
-1.7 \mathrm{mg} / \mathrm{kg}^{\ddagger} \\
2 \mu \mathrm{g} / \mathrm{kg} / \mathrm{min} \\
1.7 \mathrm{mg} / \mathrm{kg} \\
5 \mu \mathrm{g} / \mathrm{kg} / \mathrm{min} \\
200 \mu \mathrm{g} / \mathrm{kg} / \mathrm{min} \\
-\end{array}$ & $\begin{array}{c}26 \mathrm{ng} / \mathrm{kg} / \mathrm{min} \\
0.8 \mu \mathrm{g} / \mathrm{kg} / \mathrm{min} \\
0.7 \mathrm{mg} / \mathrm{kg} \\
19 \mu \mathrm{g} / \mathrm{kg} / \mathrm{min} \\
2.9 \mathrm{mg} / \mathrm{kg} / \mathrm{min} \\
1 \mathrm{mg} / \mathrm{kg} / \mathrm{hr} \\
0.6 \mathrm{mg} / \mathrm{kg} \\
1.2 \mu \mathrm{g} / \mathrm{kg} / \mathrm{min} \\
1.2 \mathrm{mg} / \mathrm{kg} \\
3 \mu \mathrm{g} / \mathrm{kg} / \mathrm{min} \\
140 \mu \mathrm{g} / \mathrm{kg} / \mathrm{min} \\
2 \mathrm{mg} / \mathrm{kg} \\
15 \mu \mathrm{g} / \mathrm{kg} / \mathrm{min}\end{array}$ \\
\hline
\end{tabular}

$\star^{\star}$ Patients received nifedipine 5 or $10 \mathrm{mg} \mathrm{SL}$. Dose was repeated hourly until maximal effect was obtained or adverse effects occured. One patient who responded to infusion was subsequently challenged with nifedipine SL. †Diltiazem was given orally every two hours until maximal effect was obtained or adverse effect occurred. One patient who responded to infusion was challenged with diltiazem orally $\ddagger$ One patient given doses hourly for three hours. $\$ 1 \mathrm{mg} / \mathrm{kg}$ bolus then infusion. $\mathrm{O}$, orally; SL, sublingual; IV, intravenous. 
by $>100 \%$ or an absolute rate $>180 / \mathrm{min}$. A period of six hours between each of the long acting drugs and at least one hour after short acting intravenous drugs was allowed for the effect of the drugs to wear off. Oxygen and drugs were not used in combination except in one patient, who was intubated and ventilated with $100 \%$ oxygen. Patients who responded to intravenous calcium channel blockers were rechallenged with sublingual or oral medication to assess the future efficacy of long-term oral medication.

Passive distension and recruitment of pulmonary arteries or an increase in cardiac index can affect the calculation of pulmonary vascular resistance without necessarily indicating a decrease in vascular tone. ${ }^{14}$ Also, a significant drop in systemic blood pressure can be associated with a decrease in pulmonary artery pressure without necessarily influencing the pulmonary vascular bed directly. We therefore chose to define a positive response to vasodilator treatment as a decrease in the mean pulmonary artery pressure to mean systemic artery pressure ratio of $>15 \%$ with the mean pulmonary artery pressure not reaching systemic levels and no change or an increase in mean systemic artery pressure. For the oxygen response, the baseline values of the catheter laboratory were used whereas for a vasodilator drug, the baseline value used was the one measured in the intensive care unit just before the tests on that particular agent.

Statistical analyses were performed with an Apple Macintosh computer and the StatView statistic program. The acute maximal effect of the vasodilators are presented as percentage change from pretreatment values. Haemodynamic values were compared between groups ( $1 v 2$, responders $v$ nonresponders, patients experiencing or not experiencing adverse effects) with two tailed unpaired Student's $t$ tests. Log rank statistics were used to compare survival curves.

\section{Results}

POPULATION

Table 1 shows the patients' clinical and demographic data. The eight group 1 patients tended to be slightly older (range $4 \cdot 1-16 \cdot 1$, median $=6$ years) than the six group 2 patients $(2 \cdot 0-11 \cdot 1, \quad$ median $=5$ years $)$. Seventy five per cent of the patients were females. The mean duration of follow up in group 1 was 16 months and in group 231 months. Patients in group 1 tended to have more symptoms at the time of referral. There were two $(25 \%)$ group 1 patients with familial primary pulmonary hypertension; one (patient 5) whose mother died at 33 years of age of primary pulmonary hypertension associated with veno-occlusive disease and a second (patient 3) whose paternal aunt died in early adulthood and her half sister (same father but different mother) had recently been diagnosed at 22 months of age, both with primary pulmonary hypertension.

Group 2 was composed of patients with different congenital cardiac malformations (table 1). With the exception of two patients who underwent closure of a ventricular septal defect at 2 years and patient 3 ligation of a patent ductus arteriosus at 4 years 3 months) all were repaired at a time when their pulmonary vascular bed should have been protected.

\section{HAEMODYNAMICS}

Table 2 shows the haemodynamic assessment of group 2 patients, before their definitive surgical correction and the evaluation of pulmonary vascular changes on lung biopsy. The pulmonary vascular resistance index was abnormal $\left(\geqslant 4\right.$ Wood units $\mathrm{m}^{2}$ ) in the four patients in whom it could be calculated.

Table 3 shows the baseline haemodynamic assessment at the time of inclusion in the study and the outcome of all patients. There were no significant differences between groups 1 and 2 in any of the measured or calculated values but there was a trend toward higher values of pulmonary vascular resistance (mean (SD) of $31 \cdot 7(20) v 21 \cdot 8(10)$ Wood units $\mathrm{m}^{2}$ ) and mean (SD) pulmonary artery pressure $(75(24) \mathrm{mm} \mathrm{Hg} v 59(20) \mathrm{mm}$ $\mathrm{Hg}$ ) in group 1 compared with group 2 . The difference may have been significant in a larger group. Three patients in group 1 and one patient in group 2 had a high pulmonary arterial wedge pressure ( $\geqslant 12 \mathrm{~mm} \mathrm{Hg}$ ) but catheter and Doppler echocardiographic investigations ruled out pulmonary venous obstruction and left sided abnormalities. Hypoxaemia $\left(\mathrm{Po}_{2}<10.6 \mathrm{kPa}\right)$ while breathing room air was documented in $5 / 8$ patients in group 1 and in $2 / 6$ patients in group 2 . None had lung disease and in only one patient could it be explained by a patent foramen ovale. All our patients except two had a mixed venous saturation $<63 \%$ reflecting decreased cardiac output. One patient had a mean right atrial pressure $>10 \mathrm{~mm} \mathrm{Hg} \mathrm{sec-}$ ondary to congestive heart failure. The mean right atrial pressure was not significantly different in the non-responder $v$ the responder group or the groups experiencing or not experiencing adverse effects.

\section{VASODILATORS}

Table 4 shows the list of the 11 different pharmacological vasodilators tried, the way they were given, and the range of doses used. Table 5 details the response of individual patients to oxygen and pharmacological agents and indicates the percentage change in mean pulmonary to mean systemic arterial pressure ratio and the absolute values in cases where there was a positive response. Treatment with $100 \%$ oxygen caused a drop in mean pulmonary artery pressure to mean systemic artery pressure ratio $>15 \%$ with mean pulmonary pressure becoming less than the systemic pressure in $2 / 7$ patients from group 1 and $3 / 6$ from group 2 . All responders to oxygen and $50 \%$ of the non-responders to oxygen responded to one or more vasodilator drug.

From the 58 drug trials, we found 13 posi- 
Table 5 Response to vasodilators judged by a $>15 \%$ change in $\mathrm{mPAP} / \mathrm{mSAP}$ ratio

\begin{tabular}{|c|c|c|c|c|c|c|c|c|c|c|c|c|c|c|c|c|}
\hline \multirow[b]{2}{*}{ Case } & \multirow[b]{2}{*}{$\mathrm{O}_{2}$} & \multirow{2}{*}{$\begin{array}{l}\text { Percentage change } \\
m P A P / M S A P \\
(m m H g)\end{array}$} & \multicolumn{11}{|c|}{ Drugs } & \multirow{2}{*}{$\begin{array}{l}\text { Total } \\
\text { drug trials } \\
(n)\end{array}$} & \multirow{2}{*}{$\begin{array}{l}\text { Total }+v e \\
\text { response }\end{array}$} & \multirow{2}{*}{$\begin{array}{l}\text { Percentage change } \\
m P A P / m S A P^{\star} \\
(m m ~ H g)\end{array}$} \\
\hline & & & $P$ & $N$ & $D$ & $T$ & $H$ & $S$ & $C$ & $\mathrm{Ni}$ & $P h$ & Phe & $A$ & & & \\
\hline \multicolumn{17}{|c|}{ Group 1} \\
\hline 1 & 0 & & - & 0 & - & 0 & 0 & 0 & 0 & 0 & 0 & 0 & 0 & 2 & $0 / 2$ & \multirow{6}{*}{$\begin{array}{l}32 \text { and } 17 \\
54 / 75-35 / 75 \text { and } 87 / 87-75 / 88 \\
20 \text { and } 28 \\
65 / 78-50 / 79 \text { and } 65 / 68-55 / 80\end{array}$} \\
\hline 2 & - & & 0 & + & $+\dagger$ & 0 & 0 & - & 0 & - & 0 & 0 & 0 & 4 & $2 / 4$ & \\
\hline 3 & + & $\begin{array}{l}44 \\
55 / 65-40 / 85\end{array}$ & 0 & - & + & 0 & - & - & - & + & 0 & - & 0 & 7 & $2 / 7$ & \\
\hline 4 & - & \multirow{5}{*}{$\begin{array}{l}26 \\
100 / 95-74 / 95\end{array}$} & - & - & $\overline{-}$ & 0 & 0 & 0 & - & 0 & 0 & 0 & 0 & 4 & $0 / 4$ & \\
\hline 5 & - & & - & $\overline{0}$ & 0 & 0 & 0 & 0 & 0 & 0 & 0 & 0 & 0 & 2 & $0 / 2$ & \\
\hline 6 & - & & - & 0 & 0 & 0 & 0 & 0 & 0 & 0 & 0 & 0 & 0 & 1 & $0 / 1$ & \\
\hline 7 & + & & 0 & + & 0 & 0 & - & 0 & - & 0 & 0 & 0 & 0 & 3 & $1 / 3$ & \multirow[t]{2}{*}{$\begin{array}{l}18 \\
83 / 90-65 / 85\end{array}$} \\
\hline 8 & - & & 0 & - & 0 & 0 & - & - & 0 & Group & $\overline{2}$ & 0 & 0 & 5 & $0 / 5$ & \\
\hline 1 & + & \multirow{4}{*}{$\begin{array}{l}34 \\
37 / 60-30 / 90 \\
19 \\
48 / 65-43 / 72\end{array}$} & + & - & - & 0 & 0 & 0 & - & 0 & 0 & 0 & 0 & 4 & $1 / 4$ & \multirow{8}{*}{$\begin{array}{l}30 \\
26 / 65-19 / 68 \\
32 \\
75 / 75-48 / 70 \\
26 \text { and } 48 \\
75 / 70-53 / 68 \text { and } 59 / 83-31 / 82 \\
32 \\
43 / 78-30 / 80 \\
23 \text { and } 34 \\
82 / 65-68 / 70 \text { and } 87 / 60-65 / 69 \\
23 \\
82 / 73-72 / 84\end{array}$} \\
\hline 2 & + & & 0 & - & 0 & - & - & 0 & - & + & - & 0 & 0 & 6 & $1 / 6$ & \\
\hline 3 & - & & - & - & - & 0 & 0 & 0 & + & 0 & 0 & 0 & + & 5 & $2 / 5$ & \\
\hline 4 & - & & - & + & 0 & - & - & 0 & 0 & - & 0 & 0 & 0 & 5 & $1 / 5$ & \\
\hline 5 & + & \multirow{4}{*}{$\begin{array}{l}25 \\
80 / 65-68 / 74\end{array}$} & 0 & + & + & 0 & 0 & - & 0 & - & 0 & 0 & 0 & 4 & $2 / 4$ & \\
\hline 6 & - & & - & - & + & 0 & - & - & 0 & - & 0 & 0 & 0 & 6 & $1 / 6$ & \\
\hline $\begin{array}{l}\text { Total } \\
\text { trials (n) }\end{array}$ & 13 & & 8 & 12 & 8 & 2 & 6 & 5 & 6 & 7 & 2 & 1 & 1 & 58 & & \\
\hline $\begin{array}{l}\text { Total t } \\
\text { response }\end{array}$ & $5 / 13$ & & $1 / 8$ & $4 / 12$ & $4 / 8$ & $0 / 2$ & $0 / 6$ & $0 / 5$ & $1 / 6$ & $2 / 7$ & $0 / 2$ & $0 / 1$ & $1 / 1$ & $13 / 58$ & & \\
\hline
\end{tabular}

*Percentage of change in the ratio of mPAP/mSAP given for each of the effective drugs. †Diltiazem tried $2.5 \mathrm{yr}$ after the first drug study. 0 , not given; - nonresponder; +, responder; P, prostacyclin; N, nifedipine; D, diltiazem; T, tolazoline; H, hydralazine; S, salbutamol; C, captopril; Ni, glyceryl trinitrate; responder; +, responder; $\mathrm{P}$, prostacyclin; N, nifedipine; D, diltiazem; T, tolazoline; H, hydralazine; S, salbutamol; C, captopril;
Ph, phentolamine; Phe, phenoxybenzamine; A, amrinone; mPAP, mean pulmonary artery pressure; MSAP, mean systemic artery pressure.

tive responses in nine different patients, three of eight in group 1 and six of six in group 2. We found no difference between responders and non-responders in their baseline haemodynamic measurements, but unfortunately pulmonary vascular resistance and cardiac index were available in only three patients. Data from lung biopsies available in some of the group 2 patients, also did not predict a difference between responders and nonresponders in this small subset of patients. Among the vasodilators tried, tolazoline, hydralazine, salbutamol, phentolamine and phenoxybenzamine were ineffective. Surprisingly, despite adequate doses (12 to $40 \mu \mathrm{g} / \mathrm{kg} / \mathrm{min}$ ) only one of eight patients responded to prostacyclin. Nifedipine was effective in four of 12, diltiazem in four of eight, captopril in one of six, and glyceryl trimitrate in two of seven patients.

\section{ADVERSE EFFECTS}

In the course of the 58 drug trials, we found six $(10 \%)$ serious adverse events in five different patients. These included haemodynamic changes causing respiratory distress, heart failure, or desaturation in the absence of a right to left shunt. Nifedipine was responsible for the most severe side effects precipitating three episodes of cardiac failure within two hours of an oral dose. In two patients (patient 5 of group 1 and patient 5 of 2) chest radiography showed pulmonary oedema and a cross sectional echocardiogram confirmed a deterioration in left ventricular function. Intubation and aggressive ventilation, as well as calcium and inotropic support were required. These patients had received either 0.7 or $1.3 \mathrm{mg} / \mathrm{kg}$ of nifedipine. In the third case (patient 3 of group 2) milder symptoms improved after supplementation with oxygen and discontinuation of the medication. This patient also experienced symptomatic hypotension with prostacyclin. Hydralazine caused a drop in saturation to the low $80 \mathrm{~s}$ in one patient (patient 8, group 1) and a second patient (patient 7, group 1) had a symptomatic 30\% decrease in mean systemic pressure associated with a $30 \%$ increase in heart rate and a $14 \%$ increase in right ventricular systolic pressure.

These five patients, when retrospectively analysed together, seem to have had worse disease than the remaining patients as judged by their significantly higher pulmonary vascular resistance $\left(39(17) v 19(9)\right.$ Wood units $\mathrm{m}^{2}$; $\mathrm{p}=0.04$ ) and higher pulmonary artery wedge pressures (12(4) $v 6$ (3) $\mathrm{mm} \mathrm{Hg}$; $\mathrm{p}=0.02$ ). Salbutamol caused an average increase of $35 \%$ in heart rate without any significant problem. No patient had recurrent pulmonary hypertension at the end of a drug trial.

\section{OUTCOME}

We found no significant difference in survival curves between groups 1 and 2 , which had similarly poor outcomes (fig 1 ). Of the group 1 patients, seven died within 2.6 years of the drug trials and one is alive 4.9 years later (table 3). Of the group 2 patients, four died within two years and two are alive after 3.8 and 8.5 years of follow up. It is possible that with a larger series of patients, improved survival would be evident in group 2 patients.

A positive response to vasodilators had a significant predictive value for survival ( $p=$ 0.005 ; fig 2). The five non-responders died within 0.7 years of follow up. Of the nine responders, six died between 0.4 and 2.6 years after the drug trials and three are alive at 3.8 to 8.2 years of follow up.

Patients who experienced serious adverse effects seemed to have more severe disease as 
Figure 1 Survival curves of patients with primary pulmonary hypertension (group 1) or pulmonary hypertension persisting or recurring after complete surgical repair of congenital heart defect (group 2). Short horizontal bars on vertical bars indicate SEM (2 $S E M=95 \% C I)$. The dotted line represents the living patients and the solid line the patients that had died at each follow up. Thus there is one living patient in group 1 and two in group 2.

Figure 2 Survival curves of responders and nonresponders to acute vasodilators. Short horizontal bars on top of the vertical bars represent the SEM (2 SEM = 95\% CI). The solid line represents dead patients and the dotted line living patients. There are three living patients in the responder group.
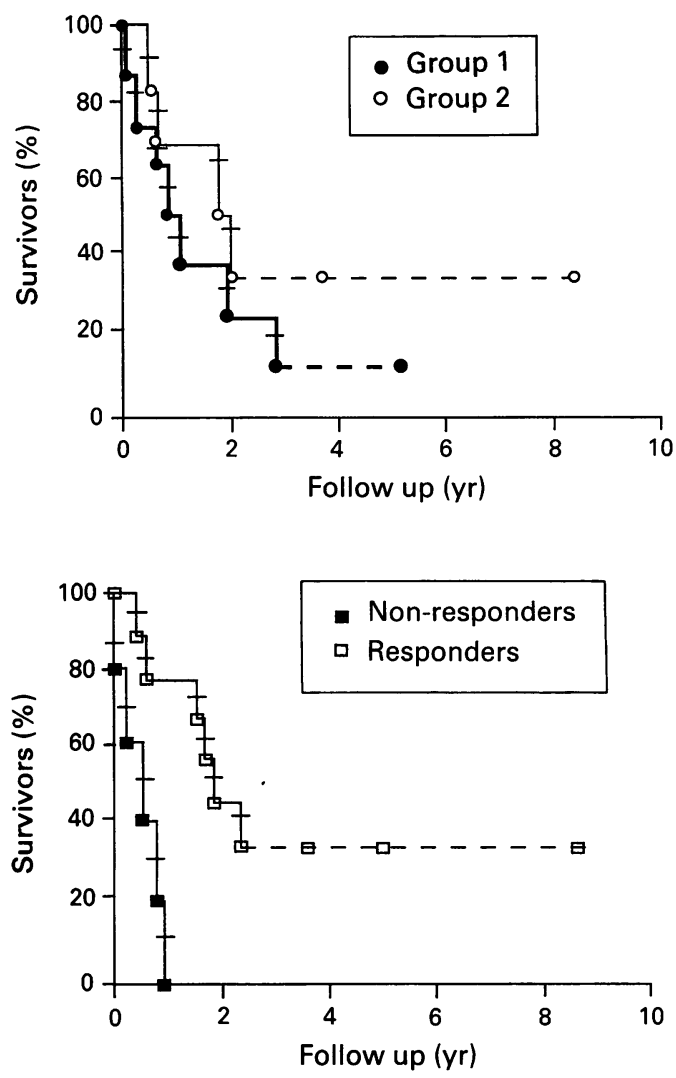

assessed by their significantly higher pulmonary vascular resistance index and mean pulmonary artery pressure but as a group their survival curve was not significantly different from the rest of the patients $(p=0.35)$.

\section{Discussion}

Primary pulmonary hypertension is a rare disease in the paediatric population ${ }^{15-17}$ and only one study describing the effect of vasodilators in children has been published in English. ${ }^{18}$ Over the past seven years, eight patients with primary pulmonary hypertension and six patients in whom pulmonary hypertension persisted or progressed after complete correction of a cardiac lesion were seen at our institution. The 14 patients limit our study, but in considering a rare disease like pulmonary hypertension we considered that important information could still be drawn from analysis of those patients. The small series could in part explain why no significant difference was seen between baseline haemodynamic evaluation of groups 1 and 2. As a trend toward higher pulmonary pressure and resistance was seen in group 1, perhaps a larger series would show a significant difference as those patients were not followed up by a cardiologist until they presented with advanced symptoms of pulmonary vascular disease. This contrasts with group 2 patients that were followed up from the time of diagnosis of their heart defect.

The second limitation of this study is that the time span over which it extended (eight years) required that we make modifications in the drug protocols that we used, in keeping with new published information, and this explains why not all drugs were given to all patients.
Contrary to some reported paediatric series $^{1517}$ females constituted most of our population, in which only one patient was beyond puberty. The mean age of our group of patients with primary pulmonary hypertension ( 8.6 years) is similar to that of Barst's series $(10.4$ years $),{ }^{18}$ but is slightly older than the series reported by Thilenius et al (4.9 years), ${ }^{15}$ and Robertson ( 0.4 years). ${ }^{16}$ A $25 \%$ incidence of positive familial history is higher than previously reported. ${ }^{19} 20$

Our hypothesis that patients with primary pulmonary hypertension presenting in the paediatric age group might be diagnosed earlier in the evolution of the disease and have vascular lesions more amenable to vasodilator treatment was not confirmed by our study. In fact, children seem to present later than adults as judged by clinical findings. Fifty per cent of our patients with primary pulmonary hypertension had had one syncopal episode at the time of presentation compared with $13 \%$ of patients in the National Institute of Health registry ${ }^{19}$ and $36 \%$ of the Mayo clinic group. ${ }^{20}$ Fifty per cent had signs of heart failure at the time of diagnosis, which had been shown in the series of Rozkovec et al to be an indicator of poor outcome with $44.4 \%$ of patients surviving less than five years presenting with right heart failure compared with $8.3 \%$ of patients surviving more than five years. ${ }^{21}$ This may be explained by the fact that children slowly and silently limit their activity making the appearance of symptoms harder to detect. The haemodynamic evaluation (mean pulmonary artery pressure, pulmonary vascular resistance index, and cardiac index) of our eight patients with primary pulmonary hypertension is comparable with that found in the 187 patients of the National Institute of Health registry. ${ }^{10}$ With the exception of two patients, all had a mixed venous saturation of $<63 \%$, a feature which Fuster et al have correlated with a three year survival of $17 \%{ }^{20}$ Surprisingly, despite more severe symptoms and a higher incidence of right ventricular failure, the mean right atrial pressure of our patients was lower than most reported adult series $^{10}$ and contrary to a previous study, ${ }^{19}$ we found no difference in mean right atrial pressure in the subgroup experiencing adverse effects compared with the others. As described in previous series, ${ }^{1014} 37 \%$ of our patients with primary pulmonary hypertension had an increased pulmonary arterial wedge or left ventricular end diastolic pressure, which we attributed to an abnormal left ventricular end diastolic pressure volume relation secondary to septal bulging and right ventricular hypertrophy. ${ }^{22}$

The survival of our patients with primary pulmonary hypertension is overall shorter ( $37 \%$ survival at one year and $12 \%$ at $2 \cdot 5$ years) than that reported in adults in the National Prospective Registry $(68 \%$ at one year, $48 \%$ at three years and $34 \%$ at five years) $)^{23}$ or by Fuster et al ( $70 \%$ survival at one year, $60 \%$ at two years, $21 \%$ at five years). ${ }^{20}$ Our results, however, are in keeping with previous paediatric series, one of which showed a 
$36 \%$ survival rate at one year in patients $<14$ years of age, ${ }^{20}$ and a second study that showed that only $25 \%$ of children survive $>$ one year after the onset of symptoms. ${ }^{15}$

Numerous definitions of a positive response to vasodilators have been used but as suggested by Rich ${ }^{14}$ and Barst, ${ }^{18}$ to stop or slow down the pathological process of pulmonary hypertension, it is important to selectively decrease pulmonary artery pressure and this rationale justified the use of our definition. Numerous drugs (4.1 trials a patient) were tried in our study, but most positive responses were related to calcium channel blockers. Although used less often, beneficial effects were also noted with captopril, triglyceryl nitrate, and amrinone. We were surprised by the poor results obtained with infusion of prostacyclin despite the use of a higher dose than previously reported ${ }^{24-26}$ a positive response was found in only one of nine trials (11\%). This experience seems at first different from the $70 \%$ incidence of positive response (decrease in pulmonary vascular resistance of $>20 \%$ ) reported by Long and Rubin, ${ }^{25}$ the $30 \%$ incidence reported by Palevsky et $a l,{ }^{24}$ and the $55 \%$ incidence in Barst's paediatric series. ${ }^{18}$ In the more extensive series of Rubins et al, mean pulmonary artery pressure did not decrease with prostacyclin and the $27 \%$ reduction in pulmonary vascular resistance was based on an increase in cardiac output. ${ }^{27}$ Furthermore, we did not find prostacyclin as good a screening agent as reported in other series ${ }^{182425}$ as three of our non-responders to prostacyclin responded to either nifedipine, diltiazem, or captopril.

Only five of our acute responders to vasodilators were treated chronically and therefore no conclusion on the long-term effect of this treatment can be drawn. Nor can we conclude whether some of the improved outcome in some of the responders may have been due to chronic treatment with a vasodilator. But our data would support Palevsky and Fishman who suggested that as "labour-intensive and time-consuming" as those studies can be, incremental doses of multiple agents should be used to find effective drugs available for chronic treatment. ${ }^{28}$ Consequently, we suggest that patients first receive prostacyclin then, regardless of their response, diltiazem and nifepidine if their left ventricular function is normal. If a patient does not respond to prostacyclin it is important to titrate the dose of the other vasodilator agents very carefully as the obstruction in the vascular bed may be fixed and the inability to recruit vessels may lead to a sudden drop in cardiac output as the systemic vascular bed vasodilates. If there is no response to prostacyclin or calcium channel blockers, we would still try other vasodilators such as captopril or amrinone, given our limited but positive experience. Systemic vasodilatation itself may improve cardiac output and the symptoms of the patient, although this is unlikely to be of long-term benefit.

Similar to reports by Weir et al ${ }^{19}$ and Rich et $a l^{29}$ we found no significant differences in baseline haemodynamic measurements that would predict a positive response to vasodilator treatment. But if despite numerous drug trials a patient is classified as a non-responder, our experience as well as that of Rich et $a^{30}$ would suggest that those patients will have a significantly shorter survival than the responders.

By contrast with most vasodilator studies reported ${ }^{18242731}$ we experienced serious side effects in five of $14(35 \%)$ patients during the course of six of $58(10 \%)$ drug trials. This is in keeping, however, with the report by Weir et al, ${ }^{19}$ in which 29 of $104(28 \%)$ patients had side effects during 32 of $417(7 \cdot 6 \%)$ drug trials. Six of the patients in the series of Weir et al required treatment for hypotensive episodes and two died after being given nifedipine or phentolamine. ${ }^{19}$ Weir et al ${ }^{19}$ also found that their patients with adverse effects to vasodilators probably had more severe disease on the basis of significantly higher mean right atrial and mean pulmonary arterial pressures. We also noted that the negative inotropic effect of calcium channel blockers may be particularly detrimental to patients in whom right ventricular dilatation and bowing of the interventricular septum compromises left ventricular function. It was suggested by Rich and Brundage, ${ }^{31}$ who did not find left ventricular dysfunction in their series despite the use of high dose calcium channel blockers, that this detrimental effect might be prevented if digoxin was given concomitantly. Although, in our series, survival was not significantly shorter in patients experiencing severe side effects, all these children died within two years of their drug trial $(1 \cdot 3(0.4)$ years). It is possible that a larger series would show a difference in survival between the two groups.

In conclusion, our data suggest that children with primary pulmonary hypertension present to the cardiologist at a relatively young age and with advanced disease. Pulmonary hypertension persisting after correction of a congenital heart disease also seems to be a subgroup with a poor survival. A positive response to drugs was found despite no effect with oxygen. A significant number of patients have a positive response to acute vasodilators, with calcium channel blockers being the most effective, but the effect of long-term treatment remains to be studied in paediatric patients. Finally according to our results a non-responder to acute vasodilators has a shorter survival time than a responder. In cases where lung transplantation may be a therapeutic option, the lack of response to acute vasodilators might suggest more urgent surgical intervention.

1 Shettiger UR, Hultgren $\mathrm{HN}$, Specter $M$, et al. Primary pulmonary hypertension: Favorable effect of isoproterenol. N Engl f Med 1976;295:1414-5.

2 Klinke WP, Gilbert JAL. Diazoxide in primary pulmonary hypertension. N Engl f Med 1980;302:91-2.

3 Packer MB, Greenberg B, Massie B, et al. Deleterious effects of hydralazine in patients with primary pulmonary hypertension. $N$ Engl f Med 1982;306:1326-31. 
4 Packer $M$. Is it ethical to administer vasodilator drugs to patients with primary pulmonary hypertension? Chest 1989;95:1173-4.

5 McManigle JE, Tenholder MF. Treatment for primary pulmonary hypertension: back to the future. Chest 1989 96:901-5.

6 Voelkel NF, Weir EK. Etiologic mechanisms in primary pulmonary hypertension. In: Weir EK, Reeves JT, eds. pulmonary hypertension. In: Weir EK, Reeves JT, eds. Pulmonary vascular physiology and pat

7 Calhoon JH, Grover FL, Gibbons WJ, et al. Single lung transplantation: alternative indications and technique. f Thorac Cardiovasc Surg 1991;101:816-25.

8 Starnes VA, Stinson EB, Oyer PE, et al. Single lung transplantation: a new option for patients with pulmonary hypertension. Transplant Proc 1991;23:1209-10.

9 Pasque MK, Elbert PT, Kaiser LR, Cooper JD. Singlelung transplantation for pulmonary hypertension: three month hemodynamic follow-up. Circulation 1991;84: 2275-79.

10 Rich S, Dantzker DR, Ayres SM, et al. Primary pulmonary hypertension: a national prospective study. Ann

11 Heath D, Edwards JE. The pathology of hypertensive pulmonary vascular disease. Circulation 1958;18:533-47.

12 Rabinovitch M, Haworth SG, Castaneda AR, et al. Lung biopsy in congenital heart disease: a morphometric approach to pulmonary vascular disease. Circulation 1978;58:1107-22.

13 Grossman W. Clinical measurement of vascular resistance and assessment of vasodilator drugs. In: Grossman W, ed. Cardiac catheterization and angiography. Philadelphia: Lea and Febiger, 1991:143-51.

14 Rich S. Primary pulmonary hypertension: modes of diagnosis and aggressive treatment with vasodilators. diagnosis and aggressive trea

15 Thilenius OG, Nadas AS, Jockin H. Primary pulmonary vascular obstruction in children. Pediatrics 1965;36: $75-87$.

16 Robertson B. Idiopathic pulmonary hypertension in infancy and childhood. Acta Pathologica et Microbiologica Scandinavica 1971;79:217-27.

17 Perkin RM, Anas NG. Pulmonary hypertension in paediatric patients. $\mathcal{F}$ Pediatr 1984;105:511-22.

18 Barst RJ. Pharmacologically induced pulmonary vasodilatation in children and young adults with primary pulmonary hypertension. Chest 1986;89:497-503.

19 Weir EK, Rubin LJ, Ayres SM, et al. The acute administration of vasodilators in primary pulmonary hypertension. Am Rev Respir Dis 1989;140:1623-30.

20 Fuster V, Steele PM, Edwards WD, et al. Primary pulmonary hypertension: natural history and the impormonary hypertension: natural history and the

21 Rozkovec A, Montanes P, Oakley CM. Factors that influence the outcome of primary pulmonary hypertension. Br Heart F 1986:55:449-58.

22 Krayenbuehl HP, Turina J, Hess $O$. Left ventricular function in chronic pulmonary hypertension. $\mathrm{Am} \mathcal{F} \mathrm{Cardiol}$ 1978;41:1150-8.

23 D'Alonzo GE, Barst RJ, Ayres SM, et al. Survival in patients with primary pulmonary hypertenson: results from a national prospective registry. Ann Intern Med 1991;115:343-9.

24 Palevsky HI, Long W, Crow J, Fishman AP. Prostacyclin and acetylcholine as screening agents for acute pulmonary vasodilator responsiveness in primary pulmonary hypertension. Circulation 1990;82:2018-26.

25 Long WA, Rubin LJ. Prostacyclin and PGE 1 treatment of pulmonary hypertension. Am Rev Respir Dis 1987; pulmonary

26 Scott JP, Higenbottam T, Wallwork J. The acute effect of the synthetic prostacyclin analogue iloprost in primary pulmonary hypertension. Br Clin Pract 1990;44:231-4.

27 Rubin LJ, Mendoza J, Hood M, et al. Treatment of primary pulmonary hypertension with continuous intravenous prostacyclin (epoprostenol): results of a randomized trial. Ann Intern Med 1990;112:485-91.

28 Palevsky HI, Fishman AP. The management of primary pulmonary hypertension. $¥ A M A 1991 ; 265: 1014-20$.

29 Rich S, Martinez J, Lam W, Levy PS, Rosen KM. Reassessment of the effects of vasodilator drugs in primary pulmonary hypertension: guidelines for determining a pulmonary vasodilator response. Am Heart $¥ 1983$; ing a pulmo

30 Rich S, Brundage BH, Levy PS. The effect of vasodilator therapy on the clinical outcome of patients with primary pulmonary hypertension. Circulaion 1985;71:1191-6.

31 Rich S, Brundage BH. High-dose calcium channel-blocking therapy for primary pulmonary hypertension: evidence for long-term reduction in pulmonary arterial pressure and regression of right ventricular hypertrophy. Circulation 1987;76:135-41. 